\title{
Between-Domain Relations of Academic Emotions: Does Having the Same Instructor Make a Difference?
}

\author{
Thomas Goetz \\ University of Konstanz, Germany and Thurgau University of Teacher \\ Education, Switzerland \\ Anne C. Frenzel \\ University of Augsburg, Germany \\ Oliver Lüdtke \\ Max Planck Institute for Human Development, Germany \\ Nathan C. Hall \\ McGill University, Canada
}

Previous research indicates that academic emotions are largely organized along domain-specific lines. In the present study $(N=1,687$; Grades 8/11), the authors explored the domain specificity of academic emotions in terms of the moderating influence of having the same versus a different course instructor across domains. The authors evaluated discrete emotions consisting of enjoyment, pride, anxiety, anger, and boredom as experienced in the academic domains of mathematics and physics. Consistent with previous findings, between-domain relations for these emotions were relatively weak. These relations were, however, significantly stronger in classes having the same instructor in mathematics and physics compared with classes having

Address correspondence to Thomas Goetz, Empirical Educational Research, University of Konstanz, Universitaetsstr. 10, D—78457, Konstanz, Germany. E-mail: thomas.goetz@uni-konstanz.de 


\begin{abstract}
different instructors for each subject. Nevertheless, the between-domain relations in classes having the same instructor were not strong enough to disconfirm the domainspecific conceptualization of academic emotions. Last, the authors discuss directions for future research on additional factors potentially affecting the strength of betweendomain relations of academic emotions.
\end{abstract}

Keywords: academic, anger, anxiety, boredom, domain specificity, emotions, enjoyment, pride

UNTIL RECENTLY, EMOTIONAL EXPERIENCES related to learning and achievement have been largely neglected in educational research. Over the past 10 years, however, there has been an appreciable increase in theoretical and empirical contributions on the role of emotions in education (see Efklides \& Volet, 2005; Linnenbrink, 2006; Schutz \& Lanehart, 2002; Schutz \& Pekrun, 2007). One particularly intriguing aspect of academic emotions that has recently been explored is the extent to which these emotions are organized in a domain-specific manner. Emerging empirical research suggests that emotions experienced in different domains have relatively weak interrelations (Goetz, Frenzel, Pekrun, Hall, \& Lüdtke, 2007). As such, these findings raise additional questions concerning emotion-related aspects of the classroom setting that may moderate this pattern of results (e.g., subject area, grade level, classmates, instructors). In addressing this potential impact of classroom dynamics on between-domain emotion relations, the present study focused on the moderating influence of the course instructor. More specifically, this study explored the extent to which the strength of relations between emotional experiences across domains changed as a function of having the same or a different teacher in these domains.

\title{
Between-Domain Relations of Academic Emotions
}

From a theoretical perspective, emotional experiences are generally assumed to have a high degree of domain specificity (Goetz et al., 2007). This finding is common when evaluating psychosocial constructs across different achievement domains, with weak between-domain relations suggesting that such variables are generally organized along domain-specific lines. In particular, weak betweendomain relations have been found for self-efficacy expectancies, causal attributions, academic self-concepts, task values, and achievement goals (e.g., Abu-Hilal \& Bahri, 2000; Bong, 2001; Bong \& Skaalvik, 2003; Marsh, 1984, 1986, 1993; Marsh \& Yeung, 1996; Möller \& Köller, 2001; Stevenson \& Newman, 1986). Consistent with the theoretical models underlying these related constructs, it is assumed that the appraisals implied by expectancies, attributions, self-concepts, values, and goals are of primary importance for the arousal of emotions (Pekrun, 2000, 2006; Roseman, 2001; Roseman \& Smith, 2001; Scherer, 2001; Weiner, 
1985). As such, the situational specificity of these appraisals further implies that resulting emotions, including those experienced by students in an academic context, should also demonstrate a considerable degree of situational specificity.

In line with these theoretical assumptions, results from recent empirical research suggest that academic emotions are organized in a primarily domain-specific manner (Goetz, Cronjaeger, Frenzel, Lüdtke, \& Hall, 2010; Goetz, Frenzel, Hall, \& Pekrun, 2008; Goetz, Frenzel, Pekrun, \& Hall, 2006; Goetz et al., 2007; Goetz, Pekrun, Hall, \& Haag, 2006; Marsh, 1988; Marsh \& Yeung, 1996). In a recent study, Goetz et al. (2007) investigated the between-domain relations for the emotions enjoyment, pride, anxiety, anger, and boredom with respect to the academic domains of mathematics, physics, German, and English (Grades 8 and 11, $n \mathrm{~s}=$ 307 and 235, respectively). Consistent with findings for related psychosocial constructs, the between-domain relations observed for these academic emotions were generally weak.

\section{Moderators of Between-Domain Relations of Academic Emotions}

Subject domain. Goetz et al. (2007) found stronger between-domain relations for emotions experienced in similar subject domains (e.g., the quantitative domains of mathematics and physics) compared with emotions experienced in more disparate domains (e.g., mathematics and English). Although none of the relations observed was large enough to cast doubt on the domain-specific organization of academic emotions, these findings suggest that the content of a given domain, involving domain value, content difficulty, as well as self-concepts and abilities related to this domain (cf. Goetz et al., 2010; Goetz et al., 2008), can moderate the strength of between-domain relations.

Grade level. Marsh and Ayotte's (2003) differential distinctiveness hypothesis stated that constructs (e.g., self-concept of abilities, interests) showing strong between-domain differences in young children should become more differentiated with age. Conversely, this hypothesis suggested that for constructs that are strongly associated across domains in young children, these between-domain correlations should show much weaker age-related declines, be stable over time, or even increase in magnitude with increasing age. In line with these theoretical assumptions, empirical results have shown that the weak relations between emotions pertaining to quantitative and verbal subjects were even weaker in Grade 11 relative to Grade 8 , or were positively related in Grade 8 yet negatively related in Grade 11 (Goetz et al., 2007). In contrast, the between-domain relations of emotions involving the quantitative domains of mathematics and physics were relatively strong in Grade 8 and were equally as strong or stronger in Grade 11 . 
Classroom composition. Recent research has further suggested that classmates are important antecedents of academic emotional experiences (e.g., Butler, 1989; Frenzel, Pekrun, \& Goetz, 2007). For example, peer-related classroom dynamics involving competition levels and peer support have been found to significantly predict students' academic emotions. As such, staying with the same classmates for each subject versus changing classmates across subjects can be assumed to moderate the strength of between-domain relations of students' emotional experiences.

Classroom instruction. Students' interaction with their course instructors is also assumed to be an especially critical emotion-inducing element of the classroom setting that may be relevant to the between-domain relations of academic emotions (e.g., Brophy \& Good, 1986; Daschmann, Goetz, \& Stupnisky, in press; Frenzel, Goetz, Lüdtke, Pekrun, \& Sutton, 2009). More specifically, students' exposure to the same instructor across domains represents an additional classroom dynamic that could moderate the pattern of between-domain relations among students' emotional experiences.

Various processes have been cited to explain how students' interactions with teachers can affect their emotional experiences. One explanation is referred to as "emotional contagion" (Hatfield, Cacioppo, \& Rapson, 1994) and involves immediate, unconscious emotional responses to the emotions "emitted" by an instructor. Alternative explanations involve teaching style (e.g., clarity, structure, enthusiasm; Patrick, Hisley, Kempler, \& College, 2000), social-cognitive learning processes (e.g., teacher as a model for problem solving; Bandura, 1977; Pekrun, 2000, 2006), and social construction processes (e.g., effects of intrinsic/extrinsic teacher motivation on students' skill acquisition and emotions; Wild, Enzle, \& Hawkins, 1992; Wild, Enzle, Nix, \& Deci, 1997). Regardless of the conceptual paradigm involved, existing research underscores the importance of teachers with respect to students' emotional experiences, and it highlights the potential moderating effects of cross-domain exposure to the same instructor on the between-domain relations of academic emotions.

\section{The Present Research}

The present study represents an investigation into the effects of the instructor on the between-domain relations of academic emotions, namely the emotions of enjoyment, pride, anxiety, anger, and boredom in the domains of mathematics and physics. More specifically, this study explored the extent to which the strength of relations between emotional experiences in mathematics and physics differed as a function of having the same or a different teacher in each domain. Given that teachers are assumed to have a considerable influence on students' emotions 
concerning the topic of instruction, we hypothesized that class sections having the same instructor for both mathematics and physics should show stronger betweendomain emotion relations than class sections having different instructors for each domain. In addition to the emotion measures, we also evaluated achievement outcomes (grades) as outcomes in our between-domain analyses to allow for comparisons with the emotion results.

We collected data in German high schools (school type: Gymnasium). In the German secondary school system, instructors typically teach two different subjects, with mathematics and physics representing a typical combination. Although instructors usually teach mathematics and physics to different class sections, they also occasionally teach both subjects to the same class section. Approximately 1 in 4 class sections has the same instructor for both mathematics and physics. Another critical characteristic of the German secondary school system is that students typically stay with the same classmates across all subjects, including mathematics and physics. As such, the German high school sample we assessed in this study represents an ideal population for exploring the moderating impact of having the same instructor on the strength of between-domain emotion relations because of the potential moderating role of classmates being controlled for.

With respect to subject area, we investigated the present study's hypothesis in two domains that are strongly related in terms of course content: mathematics and physics. We selected these domains to evaluate the moderating influence of course instruction across related domains in which already significant between-domain relations among students' emotions could be further promoted. To further account for the moderating role of students' age concerning between-domain relations (cf., differential distinctiveness hypothesis; Marsh \& Ayotte, 2003), students' grade level was also controlled for in our analysis.

\section{METHOD}

\section{Sample and Data Collection}

The sample consisted of 1,687 German high school students (44\% female, $56 \%$ male) with a mean age of 15.68 years ( $S D=1.64$ years). With respect to grade levels, 973 students ( $44 \%$ female, $56 \%$ male) were from Grade 8 ( $M$ age $=14.37$ years, $S D=0.57$ years, range $=12.17-17.75$ years $)$, and 714 students $(43 \%$ female, $57 \%$ male) were from Grade 11 ( $M$ age 17.46 years, $S D=0.64$ years, range $=16.17-20.58$ years $)$. Participants were recruited from a total of 72 classes (40 classes in Grade 8, whereas 32 classes in Grade 11; for class size, $M=$ 23.43, $S D=4.71$ ). Data were collected during the second part of the academic year (March through April, 2006) and was conducted by trained testing personnel using fully standardized student questionnaires. We observed a negligible amount 
of missing questionnaire data as a result of student nonresponse $(0.5 \%$ missing data at the item level).

\section{Emotion Measures}

The selection of emotions to be assessed was based on Goetz et al.'s (2007) study in which the between-domain relations of academic emotions was initially investigated. ${ }^{1}$ To measure the academic emotions of enjoyment, pride, anxiety, anger, and boredom in the domains of mathematics and physics, emotion scales concerning students' feelings toward classroom learning were adapted from the mathematics version of the Achievement Emotions Questionnaire (Pekrun, Goetz, \& Frenzel, 2005). Parallel item wordings were used to assess these five emotional experiences in each domain (four items per scale). Sample items for each domain are as follows:

Enjoyment: "I am looking forward to [domain] classes."

Pride: "I am proud of the contributions I make in [domain] classes."

Anxiety: "I feel tense and nervous in [domain] classes."

Anger: "I am angry in [domain] classes."

Boredom: "I get bored in [domain] classes."

The response format consisted of a 5-point Likert-type scale ranging from 1 (strongly disagree) to 5 (strongly agree). In Table 1, the means, standard deviations, and Cronbach's alphas are provided for all 10 emotion scales $(5$ emotions $\times 2$ domains). Zero-order correlations among all study measures are presented in Table 2.

\section{Academic Achievement}

We assessed achievement in mathematics and physics using students' midterm grades. In the German school system, midterm grades are typically based on one written exam in each subject area during the first half of the academic year, combined with scores on course-specific oral exams. Grades are reported on a 6point Likert-type scale ranging from 1 (very good) to 6 (insufficient), with higher numbers representing poorer achievement. To allow for coefficients involving these achievement measures to be interpreted in a more intuitive manner, we inverted students' grades such that higher numbers indicated better performance.

\footnotetext{
${ }^{1}$ Although the present study is strongly related to the study by Goetz, Frenzel, Pekrun, Hall, and Lüdtke (2007) with respect to the constructs under investigation, the present analyses are based on an entirely different data set. Further, Goetz et al. did not assess whether classes had a different or the same instructor in mathematics and physics.
} 
TABLE 1

Descriptive Statistics for Academic Emotion and Achievement Measures

\begin{tabular}{|c|c|c|c|c|c|c|c|c|c|c|c|c|}
\hline \multirow[b]{3}{*}{ Scale } & \multicolumn{6}{|c|}{ Grade 8} & \multicolumn{6}{|c|}{ Grade 11} \\
\hline & \multicolumn{3}{|c|}{$\begin{array}{l}\text { Different } \\
\text { instructor } \\
(\mathrm{n}=699)\end{array}$} & \multicolumn{3}{|c|}{$\begin{array}{c}\text { Same } \\
\text { instructor } \\
(\mathrm{n}=274)\end{array}$} & \multicolumn{3}{|c|}{$\begin{array}{l}\text { Different } \\
\text { instructor } \\
(\mathrm{n}=551)\end{array}$} & \multicolumn{3}{|c|}{$\begin{array}{c}\text { Same } \\
\text { instructor } \\
(\mathrm{n}=163)\end{array}$} \\
\hline & $M$ & $S D$ & $\alpha$ & $M$ & $S D$ & $\alpha$ & $M$ & $S D$ & $\alpha$ & $M$ & $S D$ & $\alpha$ \\
\hline \multicolumn{13}{|l|}{ Enjoyment } \\
\hline Mathematics & 2.59 & 1.12 & .90 & 2.70 & 1.17 & .91 & 2.87 & 1.20 & .92 & 3.06 & 1.16 & .94 \\
\hline Physics & 2.80 & 1.10 & .90 & 2.98 & 1.10 & .91 & 2.60 & 1.09 & .91 & 2.76 & 1.16 & .94 \\
\hline \multicolumn{13}{|l|}{ Pride } \\
\hline Mathematics & 2.80 & 1.07 & .88 & 2.82 & 1.17 & .92 & 2.82 & 1.18 & .91 & 3.12 & 1.20 & .93 \\
\hline Physics & 2.84 & 1.05 & .90 & 2.85 & 1.10 & .93 & 2.63 & 1.05 & .91 & 2.77 & 1.18 & .92 \\
\hline \multicolumn{13}{|l|}{ Anxiety } \\
\hline Mathematics & 2.08 & 1.01 & .83 & 1.94 & 0.95 & .83 & 2.03 & 1.05 & .88 & 1.92 & 1.04 & .90 \\
\hline Physics & 1.91 & 0.94 & .85 & 1.65 & 0.74 & .80 & 1.90 & 0.92 & .85 & 1.91 & 1.02 & .89 \\
\hline \multicolumn{13}{|l|}{ Anger } \\
\hline Mathematics & 2.38 & 1.07 & .81 & 2.20 & 1.01 & .79 & 2.15 & 1.03 & .83 & 1.99 & 1.00 & .85 \\
\hline Physics & 2.10 & 1.00 & .82 & 1.90 & 0.91 & .82 & 2.17 & 0.99 & .81 & 2.15 & 1.08 & .88 \\
\hline \multicolumn{13}{|l|}{ Boredom } \\
\hline Mathematics & 2.56 & 1.13 & .86 & 2.31 & 1.06 & .86 & 2.31 & 1.09 & .90 & 2.05 & 1.05 & .90 \\
\hline Physics & 2.33 & 1.13 & .89 & 2.09 & 1.05 & .91 & 2.64 & 1.21 & .91 & 2.31 & 1.15 & .92 \\
\hline \multicolumn{13}{|l|}{ Achievement } \\
\hline Mathematics & 3.33 & 1.06 & & 3.28 & 1.09 & & 3.31 & 1.16 & & 2.96 & 1.17 & \\
\hline Physics & 2.94 & 1.08 & & 2.91 & 1.01 & & 3.12 & 1.03 & & 2.95 & 1.16 & \\
\hline
\end{tabular}

Note. For the emotion scales, the means and standard deviations refer to sum scales (4 items) divided by the number of scale items each evaluated on a 5-point Likert-type scale ranging from 1 (strongly disagree) to 5 (strongly agree). Achievement values consist of inverted midterm grades (higher $=$ better grades). Descriptive values are presented separately for classes having different instructors or the same instructor for mathematics and physics.

Means and standard deviations for the achievement data are presented in Table 1 , and zero-order correlations among the achievement measures are outlined in Table 2.

\section{Instructor Consistency}

To evaluate the consistency of classroom instructors, students were asked to indicate whether they had the same or different teacher in their mathematics and physics classes. This self-report measure was included at the end of the questionnaire to prevent students from responding to the preceding emotion items with a possible understanding of the study goals. For Grade 8 students, 29 of 40 class sections indicated having different instructors, whereas for Grade 11 students, 24 of 32 class sections reported having different instructors for each subject area. 
TABLE 2

Zero-Order Correlation Coefficients among Measures

\begin{tabular}{|c|c|c|c|c|c|c|c|c|c|c|c|c|}
\hline Scale & 1 & 2 & 3 & 4 & 5 & 6 & 7 & 8 & 9 & 10 & 11 & 12 \\
\hline & \multicolumn{12}{|c|}{ Grade 8} \\
\hline 1. Enjoyment-mathematics & - & 0.28 & 0.76 & 0.28 & -0.55 & -0.11 & -0.67 & -0.15 & -0.66 & -0.14 & 0.37 & 0.17 \\
\hline 2. Enjoyment-physics & 0.62 & - & 0.24 & 0.76 & -0.07 & -0.53 & -0.10 & -0.66 & -0.14 & -0.68 & 0.07 & 0.38 \\
\hline 3. Pride-mathematics & 0.76 & 0.48 & - & 0.38 & -0.49 & -0.12 & -0.53 & -0.12 & -0.45 & -0.08 & 0.47 & 0.22 \\
\hline 4. Pride-physics & 0.52 & 0.80 & 0.62 & - & -0.07 & -0.41 & -0.08 & -0.45 & -0.10 & -0.42 & 0.11 & 0.42 \\
\hline 5. Anxiety-mathematics & -0.56 & -0.33 & -0.56 & -0.33 & - & 0.40 & 0.77 & 0.33 & 0.52 & 0.16 & -0.46 & -0.26 \\
\hline 6. Anxiety-physics & -0.34 & -0.51 & -0.34 & -0.45 & 0.66 & - & 0.30 & 0.80 & 0.15 & 0.52 & -0.17 & -0.40 \\
\hline 7. Anger-mathematics & -0.70 & -0.44 & -0.55 & -0.29 & 0.79 & 0.55 & - & 0.34 & 0.74 & 0.21 & -0.42 & -0.19 \\
\hline 8. Anger-physics & -0.49 & -0.73 & -0.32 & -0.52 & 0.55 & 0.77 & 0.66 & - & 0.25 & 0.75 & -0.16 & -0.40 \\
\hline 9. Boredom-mathematics & -0.71 & -0.48 & -0.38 & -0.28 & 0.48 & 0.36 & 0.71 & 0.56 & - & 0.26 & -0.28 & -0.11 \\
\hline 10. Boredom-physics & -0.48 & -0.76 & -0.26 & -0.49 & 0.32 & 0.50 & 0.48 & 0.81 & 0.59 & - & -0.11 & -0.25 \\
\hline 11. Achievement-mathematics & 0.45 & 0.16 & 0.55 & 0.15 & -0.42 & -0.21 & -0.43 & -0.18 & -0.26 & -0.08 & - & 0.54 \\
\hline \multirow[t]{2}{*}{ 12. Achievement-physics } & 0.31 & 0.39 & 0.37 & 0.40 & -0.36 & -0.39 & -0.32 & -0.36 & -0.19 & -0.26 & 0.64 & - \\
\hline & \multicolumn{12}{|c|}{ Grade 11} \\
\hline 1. Enjoyment-mathematics & - & 0.43 & 0.84 & 0.43 & -0.65 & -0.28 & -0.74 & -0.27 & -0.70 & -0.28 & 0.58 & 0.41 \\
\hline 2. Enjoyment-physics & 0.64 & - & 0.39 & 0.79 & -0.25 & -0.50 & -0.28 & -0.67 & -0.28 & -0.73 & 0.20 & 0.46 \\
\hline 3. Pride-mathematics & 0.83 & 0.56 & - & 0.53 & -0.63 & -0.27 & -0.63 & -0.21 & -0.51 & -0.22 & 0.62 & 0.42 \\
\hline 4. Pride-physics & 0.58 & 0.83 & 0.70 & - & -0.28 & -0.48 & -0.26 & -0.51 & -0.19 & -0.50 & 0.24 & 0.47 \\
\hline 5. Anxiety-mathematics & -0.70 & -0.54 & -0.68 & -0.50 & - & 0.54 & 0.81 & 0.38 & 0.50 & 0.24 & -0.57 & -0.37 \\
\hline 6. Anxiety-physics & -0.41 & -0.66 & -0.41 & -0.58 & 0.72 & - & 0.43 & 0.78 & 0.22 & 0.44 & -0.25 & -0.45 \\
\hline 7. Anger-mathematics & -0.77 & -0.48 & -0.65 & -0.40 & 0.87 & 0.59 & - & 0.39 & 0.72 & 0.30 & -0.57 & -0.37 \\
\hline 8. Anger-physics & -0.46 & -0.77 & -0.45 & -0.66 & 0.69 & 0.87 & 0.63 & - & 0.29 & 0.68 & -0.19 & -0.46 \\
\hline 9. Boredom-mathematics & -0.71 & -0.44 & -0.53 & -0.36 & 0.58 & 0.33 & 0.70 & 0.39 & - & 0.44 & -0.38 & -0.26 \\
\hline 10. Boredom-physics & -0.52 & -0.79 & -0.38 & -0.64 & 0.47 & 0.54 & 0.51 & 0.73 & 0.61 & - & -0.14 & -0.31 \\
\hline 11. Achievement-mathematics & 0.74 & 0.38 & 0.63 & 0.39 & -0.58 & -0.34 & -0.66 & -0.34 & -0.57 & -0.31 & - & 0.61 \\
\hline 12. Achievement-physics & 0.62 & 0.64 & 0.59 & 0.69 & -0.53 & -0.55 & -0.48 & -0.58 & -0.35 & -0.44 & 0.68 & - \\
\hline
\end{tabular}

Note. Student sample having the same teacher in mathematics and physics is shown below the diagonals (Grade $8: n=274 ; p<.05 / .01 / .001$ for $|r|>$

Note. Student sample having the same teacher in mathematics and physics is shown below the diagonals (Grade $8: n=274 ; p<.05 / .01 / .001$ for $|r|>$
$.12 / .16 / .20 ;$ Grade $11: n=163 ; p<.05 / .01 / .001$ for $|r|>.15 / .20 / .26$ ). Student sample having different teachers in mathematics and physics are shown above the diagonal (Grade $8: n=699 ; p<.05 / .01 / .001$ for $|r|>.07 / .10 / .12$; Grade $11: n=551 ; p<.05 / .01 / .001$ for $|r|>.08 / .11 / .14$ ). 
The proportion of classes in our study having the same instructor for both mathematics and physics reflects the proportion typically found in German high schools (approximately 1 in 4).

\section{Statistical Analyses}

Because the present study data had a hierarchical structure in which students are nested within classes, hierarchical linear modeling was well suited for our regression analyses. We conducted these analyses using Hierarchical Linear Modeling 6.04 (Raudenbush \& Bryk, 2002; Raudenbush, Bryk, \& Congdon, 2007). The correlations between emotional experiences in mathematics and physics were assessed by regressing one variable on the other (mathematics on physics). To investigate the impact of instructor consistency across mathematics and physics on the strength of these between-domain relations, we evaluated the effect of the instructor variable (different instructor vs. same instructor) on the mathematics/physics slopes, controlling for grade level (Grade 8 vs. Grade 11; slopes-as-outcome models).

To facilitate the interpretation of regression coefficients, all Level 1 variables (individual level; emotions related to mathematics/physics) were $z$ standardized within classes $(M=0, S D=1$ for all 72 classes; see Aiken \& West, 1991) allowing for class-specific regression coefficients to be interpreted as correlations. Concerning Level 2 variables (class level), we constructed two dummy variables to assess instructor consistency $(0=$ different instructors, $1=$ same instructor $)$, and grade level $(0=$ Grade $8 ; 1=$ Grade 11$)$. Our hierarchical linear modeling specifications were as follows:

Level 1 model:

$Y_{i j}$ [discrete emotion in physics of student $i$ in class $j$ ] $=\beta_{0 j}+\beta_{1 j} X_{i j}$ [discrete emotion in mathematics of student $i$ in class $j]+r_{i j}$

$r_{i j} \sim \mathrm{N}\left(0, \sigma^{2}\right)$

Level 2 model:

$\beta_{0 j}=\gamma_{00}$

$\beta_{1 j}=\gamma_{10}+\gamma_{11}$ (instructor consistency $)_{j}+\gamma_{12}(\text { grade level })_{j}+u_{1 j}$

$u_{\mathrm{lj}} \sim \mathrm{N}\left(0, \tau^{2}\right)$

where $r_{i j}$ and $u_{1 j}$ are normally distributed (with variance $\sigma^{2}$ and $\tau^{2}$ ) Level 1 and Level 2 residuals; $\beta_{0 j}$ and $\beta_{1 j}$ are Level 1 coefficients (intercept and slope) that predict the relation within classes. As a consequence of $z$ standardizing our Level 1 variables, the intercepts $\beta_{0 j}$ do not vary across classes and are not relevant for the present analyses. The Level 1 regression coefficients $\beta_{1 j}$ can be interpreted 
as correlation coefficients indicating the strength of the association between an emotion pertaining to mathematics versus physics.

At Level 2, these regression coefficients $\beta_{1 j}$ are predicted by the Level 2 coefficients $\gamma_{10}, \gamma_{11}$, and $\gamma_{12}$. As a consequence of $z$ standardizing our Level 1 variables and as a result of the coding of our dummy variables at Level 2 , the intercept $\gamma_{10}$ can be interpreted as the average correlation between an emotion in mathematics and physics in class sections with different instructors in Grade 8. Further, Level 2 regression coefficients $\gamma_{11}$, and $\gamma_{12}$ can be interpreted as changing the correlation within classes in an additive manner based on instructor consistency (from different instructors to the same instructor) and based on grade level (from Grade 8 to Grade 11).

\section{RESULTS}

\section{Preliminary Analyses}

Initial analyses tested for significant variation in the slopes (strength of relations of emotional experiences in mathematics and physics) across different class sections in our hierarchical regression analysis. The variance components of the slope coefficients (i.e., the strength of mathematics/physics relations varied significantly across class sections) were statistically significant for enjoyment, $\chi^{2}(71)=96.67$, $p<.05$; pride, $\chi^{2}(71)=104.70, p<.01$; anxiety, $\chi^{2}(71)=111.10, p<.01$; anger, $\chi^{2}(71)=97.22, p<.05$; and boredom, $\chi^{2}(71)=124.75, p<.01$. For achievement, the variance component of the slope did not reach statistical significance, $\chi^{2}(71)=$ 54.67 , indicating that the relation between achievement in mathematics and physics did not vary across classes.

To illustrate the magnitude of the variation in the random slopes across class sections, Raudenbush and Bryk (2002) recommended that a 95\% plausible range of regression coefficients be calculated based on the average slope $\gamma_{10}$ and the slope standard deviation $\tau$. Under the normality assumption, approximately $95 \%$ of the classes have slopes between $\gamma_{10}-2 \times \tau$ and $\gamma_{10}+2 \times \tau$. Using this approach, the $95 \%$ intervals were $[.22 ; .66]$ for enjoyment, $[.25 ; .77]$ for pride, $[.26 ; .78]$ for anxiety, $[.23 ; .67]$ for anger, $[.10 ; .74]$ for boredom, and $[.58 ; .66]$ for achievement. These intervals can be interpreted as the range of plausible correlations of the constructs across class sections.

\section{Main Analyses}

For the academic emotions of enjoyment, pride, anxiety, anger, and boredom, the coefficients $\left(\gamma_{10}\right)$ indicating the association between mathematics and physics were all statistically significant $(p<.001)$ and ranged from .30 to .42 (see Table 3 ). These coefficients show the correlations between emotional experiences in mathematics and physics for class sections in Grade 8 having different teachers in 
TABLE 3

Relations Between Emotions and Achievement Related to Mathematics and Physics

\begin{tabular}{|c|c|c|c|c|c|c|c|c|c|c|c|c|}
\hline & \multicolumn{10}{|c|}{ Emotions-physics } & \multirow{2}{*}{\multicolumn{2}{|c|}{$\begin{array}{c}\text { Achievement- } \\
\text { physics }\end{array}$}} \\
\hline & \multicolumn{2}{|c|}{ Enjoyment } & \multicolumn{2}{|c|}{ Pride } & \multicolumn{2}{|c|}{ Anxiety } & \multicolumn{2}{|c|}{ Anger } & \multicolumn{2}{|c|}{ Boredom } & & \\
\hline & $B$ & $S E$ & $B$ & $S E$ & $B$ & $S E$ & $B$ & $S E$ & $B$ & $S E$ & $B$ & $S E$ \\
\hline \multicolumn{13}{|l|}{ Individual level } \\
\hline Enjoyment-mathematics & $.33^{* * *}$ & .03 & & & & & & & & & & \\
\hline Pride-mathematics & & & $.40^{* * *}$ & .03 & & & & & & & & \\
\hline Anxiety-mathematics & & & & & $.42^{* * *}$ & .04 & & & & & & \\
\hline Anger-mathematics & & & & & & & $.37^{* * *}$ & .03 & & & & \\
\hline Boredom-mathematics & & & & & & & & & $.30^{* * *}$ & .04 & & \\
\hline Achievement-mathematics & & & & & & & & & & & $.57^{* * *}$ & .03 \\
\hline \multicolumn{13}{|l|}{ Class level-slopes } \\
\hline Instructor consistency & $.24^{* * *}$ & .05 & $.19^{* *}$ & .05 & $.16^{* *}$ & .05 & $.21^{\text {***}}$ & .05 & $.20^{* * *}$ & .06 & .07 & .04 \\
\hline Grade level & $.12^{*}$ & .05 & $.12^{*}$ & .04 & $.13^{*}$ & .05 & .06 & .05 & $.16^{* *}$ & .05 & .08 & .04 \\
\hline
\end{tabular}

Note. $N_{\mathrm{level1}}=1,687 ; N_{\mathrm{level} 2}=72$. Level 1 variables were $z$ standardized within classes. Instructor consistency values distinguished between classes having different instructors $(0)$ or the same instructor (1) for mathematics and physics. Grade level values distinguished between Grade $8\left(0 ; n_{\text {levell }}=973\right.$; $\left.n_{\text {level2 }}=40\right)$ and Grade 11 classes $\left(1 ; n_{\text {level1 }}=714 ; n_{\text {level } 2}=32\right)$.

${ }^{*} p<.05 .{ }^{* *} p<.01 .{ }^{* * *} p<.001$. 
mathematics and physics. Level 2 effects of the instructor dummy variable (different instructor vs. same instructor) were also statistically significant for all emotions $(p<.01)$, with coefficients ranging from .16 to .24 . As such, these coefficients indicate how much stronger the correlations between emotional experiences in mathematics and physics (slopes) are for class sections having the same instructor across domains compared with those having different instructors in each domain.

Concerning our Level 2 control variable, the effects of the grade level dummy variable (Grade 8 vs. Grade 11) were statistically significant for all emotions with the exception of anger $(p<.01$ for enjoyment and boredom; $p<.05$ for pride and anxiety) with coefficients ranging from .12 to .16 . These values indicate how much stronger the correlations between emotional experiences of enjoyment, pride, anxiety, and boredom in mathematics vs. physics were for students in Grade 11 compared with those in Grade 8. The two predictors at Level 2-the instructor variable (different instructor vs. same instructor) and the grade-level variable (Grade 8 vs. Grade 11) - predicted a considerable amount of variance in the slopes. $R^{2}$ was .95 for enjoyment, .81 for pride, .45 for anxiety, .77 for anger, and .51 for boredom.

To test for potential interaction effects of the Level 2 variables, we included a Teacher $\times$ Class Level interaction term in a next step in our models. After we introduced the interaction term, effects of instructor consistency and strength of between-domain relations remained unaffected, and the interaction term did not reach statistical significance. Thus, grade level (Grade 8 vs. Grade 11) did not moderate the impact of instructor consistency (different instructor vs. same instructor) on the strength of between-domain relations of academic emotions. As such, the results of these models are not presented in further detail.

For the achievement variable, the Level 1 regression coefficient was .57 and statistically significant $(p<.001)$. This value shows the correlation between achievement in mathematics and physics for classes with different instructors for mathematics and physics in Grade 8. Neither of the two Level 2 effects was statistically significant. This finding indicates that relations between achievement in mathematics and physics (slopes) did not differ across class sections as a function of having the same or different instructor in mathematics and physics, or as a function of grade level (Grade 8 vs. Grade 11). Similar to the analyses of emotion relations, we controlled for potential interaction effects of the Level 2 variables (Teacher $\times$ Class Level). Because the interaction term did not reach statistical significance, more detailed results for these models are not presented.

\section{DISCUSSION}

The present study followed recent research showing that academic emotions are to a great extent organized along domain-specific lines, and it further addressed 
the hypothesis that between-domain emotion relations should be stronger for class sections having the same course instructor across different domains. We evaluated this hypothesis with respect to the emotions of enjoyment, pride, anxiety, anger, and boredom as experienced in the domains of mathematics and physics. We collected data in the context of the German school system in which optimal conditions exist for investigating our research questions. In German high schools, mathematics and physics are taught not only by different instructors ( $75 \%$ of classes) but also by the same instructor, with class section composition remaining constant across subject areas.

In line with our hypothesis, between-domain relations for enjoyment, pride, anxiety, anger, and boredom were significantly stronger in classes having the same instructor for both mathematics and physics compared with classes having different instructors for each subject area. These differences in the strength of betweendomain relations ranged from .16 to .24. In other words, we found betweendomain relations to be stronger by these amounts for classes having the same instructor compared with those having different instructors. Following Cohen's (1988) guidelines concerning effect sizes, the effect of having the same instructor for both mathematics and physics on the strength of observed between-domain emotion relations can be considered weak to modest.

Thus, with respect to the primary study hypothesis, these results suggest that instructor consistency across academic domains does represent an important component of the classroom setting that can mitigate the domain-specific organization of academic emotional experiences. Concerning the overall issue of domain specificity, however, our study has shown that even under circumstances of maximal similarity (e.g., related contents, older age, same classmates, same teacher), the relations between emotional experiences were small in magnitude and support a domain-specific conceptualization of academic emotions. However, our study provides initial evidence suggesting that students' interaction with teachers is an important classroom dynamic with respect to their emotional experiences, as shown by the instructor consistency variable producing strong effects across all academic emotions assessed in the study. That is, the levels of enjoyment and pride - but also anxiety, anger, and boredom — found for students with respect to mathematics was more similar to their experience in physics if they were taught by the same instructor as opposed to a different instructor.

We also evaluated the strength of between-domain relations of achievement outcomes (grades) in this study to provide an additional outcome measure against which the emotion results could be compared. Between-domain relations for achievement were stronger than those for academic emotions, and it is intriguing to note that these relations did not differ as a function of instructor consistency across domains. On the basis of previous research indicating that domain-specific emotions and achievement are strongly interrelated (Goetz et al., 2007; Goetz et al., 2008), it was expected that the strength of between-domain relations, and 
moderating influence of instructor consistency, should be similar for academic emotions and achievement. However, the present findings did not show betweendomain relations for achievement outcomes to differ as a function of instructor consistency across different academic domains.

\section{Implications for Educational Practice}

The results of the present study suggest that having the same teacher in different classes contributes significantly to students having more similar emotional experiences in these classes. Consequently, these findings are consistent with the study hypotheses in showing that teachers can have an appreciable impact on students' academic emotions. Nevertheless, previous research has indicated that teachers are often unaware of, or underestimate, their influence on their students' emotional experiences. Studies have suggested that teachers tend to view individual students' characteristics as the result of habitual, domain-general attributes (Marsh, 1993; Marsh et al., 1983; Pohlmann, Möller, \& Streblow, 2004), and thus, they are likely to underestimate the degree to which their instructional style can affect students' emotional development. In contrast, our findings provide empirical support for informing teachers of their significant impact on not only students' academic development and knowledge acquisition, but also students' emotional experiences.

Following previous research on the correlates of academic emotions, teachers' efforts toward fostering students' academic emotions should serve to promote a range of adaptive academic outcomes, given that optimal achievement emotions have been found to correspond with higher levels of subjective well-being (Diener, 2000), learning and achievement (Pekrun et al., 2002), teacher-student communication (Andersen \& Guerrero, 1998), course enrollment, and career aspirations and decision making (Wigfield et al., 2002). Consistent with these findings, it is anticipated that by encouraging teachers to adopt teaching methods that foster students' positive emotional experiences and minimize negative academic emotions, improvements in classroom dynamics as well as student motivation and achievement will be observed. Recent studies suggest that potentially effective methods for promoting adaptive emotional experiences include an enthusiastic teaching style (e.g., Frenzel et al., 2009), as well as teaching practices that are high in both clarity and structure (e.g., Patrick et al., 2000; Pekrun, 2006).

\section{Directions for Future Research}

As indicated by the significant moderation effects observed, an important avenue for further research involves the examination of additional classroom dynamics with respect to their potential impact on between-domain relations of academic 
emotions. For example, recent research suggests that classmates are important antecedents of academic emotional experiences (e.g., competition levels, peer support; see Frenzel et al., 2007). As such, future research exploring the effects of changes in classroom composition on the strength of between-domain emotion relations may provide intriguing results. Contrasting findings for schools in which students stay with the same classmates for each subject with those for schools in which classmates differ across subject areas could serve to disentangle the effects of content domain and classmates on students' academic emotions.

With the exception of research on teacher burnout (e.g., Vandenberghe \& Huberman, 1999), there is a conspicuous lack of research on teacher emotions (Schutz \& Pekrun, 2007). As such, future research on between-domain emotion relations might also investigate teachers' emotional experiences concerning the subjects they teach. For example, it is possible that instructors who teach the same students in different domains report emotional experiences that are more similar across domains than do instructors who teach different subjects to different class sections.

Last, further research on factors impacting the strength of between-domain emotion relations is warranted with respect of other important academic emotions and domains. In addition to the emotions assessed in this study, other discrete emotions such as relief, guilt, relaxation, disappointment, shame, or regret should also demonstrate a similar degree of domain specificity across subject areas. Moreover, future studies assessing students' emotions in other academic domains, such as languages, history, music, or sports, may also provide valuable insight into the generalizability of empirical findings in support of the domain-specific organization of academic emotions and moderating effects of classroom factors.

\section{AUTHOR NOTES}

Thomas Goetz is a full professor in the Department of Empirical Educational Research at the University of Konstanz (Germany) and the Thurgau University of Teacher Education (Switzerland). His research interests include students' emotions, self-regulated learning, and self-concept. Anne C. Frenzel is a full professor in the Department of Psychology at the University of Augsburg (Germany). Her research interests concern factors that may influence students' and teachers' emotions related to learning and teaching. Oliver Lüdtke is a full professor in the Department of Empirical Educational Research and Educational Psychology at the University of Tübingen (Germany). His main research interests pertain to large scale studies on students' achievement, personality development in adolescence, and multilevel analyses. Nathan C. Hall is assistant professor in the Department of Educational and Counselling Psychology at McGill University (Canada). His research interests include academic control-striving, motivation, and emotions, and developing motivational interventions to improve student development. 


\section{REFERENCES}

Abu-Hilal, M. M., \& Bahri, T. M. (2000). Self-concept: The generalizability of research on the SDQ, Marsh/Shavelson model and I/E frame of reference model to the United Arab Emirates students. Social Behavior and Personality, 28, 309-322.

Aiken, L. S., \& West, S. G. (1991). Multiple regression: Testing and interpreting interactions. Newbury Park, CA: Sage.

Andersen, P. A., \& Guerrero, L. K. (1998). Principles of communication and emotion in social interaction. In P. A. Andersen \& L. K. Guerrero (Eds.), Handbook of communication and emotion (pp. 49-96). New York: Academic Press.

Bandura, A. (1977). Social learning theory. Englewood Cliffs, NJ: Prentice Hall.

Bong, M. (2001). Between- and within-domain relations of academic motivation among middle and high school students: Self-efficacy, task-value and achievement goals. Journal of Educational Psychology, 93, 23-34.

Bong, M., \& Skaalvik, E. M. (2003). Academic self-concept and self-efficacy: How different are they really? Educational Psychology Review, 15, 1-40.

Butler, R. (1989). Interest in the task and interest in peers' work in competitive and noncompetitive conditions: A developmental study. Child Development, 60(3), 562-570.

Brophy, J., \& Good, T. L. (1986). Teacher behavior and student achievement. In M. L. Wittock (Ed.), Handbook of research on teaching (3rd ed., pp. 328-375). New York: Macmillan.

Cohen, J. (1988). Statistical power analysis for the behavioral sciences. Hillsdale, NJ: Erlbaum.

Daschmann, E. C., Goetz, T., \& Stupnisky, R. H. (in press). Testing the predictors of boredom at school. Development and validation of the Precursors to Boredom Scales. British Journal of Educational Psychology.

Diener, E. (2000). Subjective well-being. The science of happiness and a proposal for a national index. American Psychologist, 55(1), 34-43.

Efklides, A., \& Volet, S. (2005). Emotional experiences during learning: Multiple, situated and dynamic [Special issue]. Learning and Instruction, 15.

Frenzel, A. C., Goetz, T., Lüdtke, O., Pekrun, R., \& Sutton, R. E. (2009). Emotional transmission in the classroom: Exploring the relationship between teacher and student enjoyment. Journal of Educational Psychology, 101, 705-716.

Frenzel, A. C., Pekrun, R., \& Goetz, T. (2007). Perceived learning environment and students' emotional experiences: A multilevel analysis of mathematics classrooms. Learning and Instruction, 17, 478-493.

Goetz, T., Cronjaeger, H., Frenzel, A. C., Lüdtke, O., \& Hall, N. C. (2010). Academic self-concept and emotion relations: Domain specificity and age effects. Contemporary Educational Psychology, $35,44-58$.

Goetz, T., Frenzel, A. C., Hall, N. C., \& Pekrun, R. (2008). Antecedents of academic emotions: Testing the internal/external frame of reference model for academic enjoyment. Contemporary Educational Psychology, 33, 9-33.

Goetz, T., Frenzel, A. C., Pekrun, R., \& Hall, N. C. (2006). The domain specificity of academic emotional experiences. Journal of Experimental Education, 75(1), 5-29.

Goetz, T., Frenzel, C. A., Pekrun, R., Hall, N. C., \& Lüdtke, O. (2007). Between- and withindomain relations of students' academic emotions. Journal of Educational Psychology, 99(4), 715733.

Goetz, T., Pekrun, R., Hall, N. C., \& Haag, L. (2006). Academic emotions from a social-cognitive perspective: Antecedents and domain specificity of students' affect in the context of Latin instruction. British Journal of Educational Psychology, 76, 289-308.

Hatfield, E., Cacioppo, J. T., \& Rapson, R. L. (1994). Emotional contagion. Cambridge, England: Cambridge University Press. 
Linnenbrink, E. A. (Ed.). (2006). Emotion research in education: Theoretical and methodological perspectives on the integration of affect, motivation, and cognition [Special issue]. Educational Psychology Review, 18.

Marsh, H. W. (1984). Relations among dimensions of self-attribution, dimensions of self-concept, and academic achievements. Journal of Educational Psychology, 76, 1291-1308.

Marsh, H. W. (1986). Verbal and math self-concept: An internal/external frame of reference model. American Educational Research Journal, 23, 129-149.

Marsh, H. W. (1988). The content specificity of math and English anxieties: The high school and beyond study. Anxiety Research, 1, 137-149.

Marsh, H. W. (1993). Academic self-concept: Theory measurement and research. In J. Suls (Ed.), Psychological perspectives on the self (Vol. 4, pp. 59-98). Hillsdale, NJ: Erlbaum.

Marsh, H. W., \& Ayotte, V. (2003). Do multiple dimensions of self-concept become more differentiated with age? The differential distinctiveness hypothesis. Journal of Educational Psychology, 94(4), 687-706.

Marsh, H. W., Smith, I. A., \& Barnes, J. (1983). Multitrait and multimethod analysis of the SelfDescription Questionnaires: Student-teacher agreement on multidimensional ratings of student self-concept. American Educational Research Journal, 20, 333-357.

Marsh, H. W., \& Yeung, A. S. (1996). The distinctiveness of affects in specific school subjects: An application of confirmatory factor analysis with the National Educational Longitudinal Study of 1988. American Educational Research Journal, 33(3), 665-689.

Möller, J., \& Köller, O. (2001). Dimensional comparisons: An experimental approach to the internal/external frame of reference model. Journal of Educational Psychology, 93, 826-835.

Patrick, B. C., Hisley, J., Kempler, T., \& College, G. (2000). “What's everybody so excited about?”: The effects of teacher enthusiasm on student intrinsic motivation and vitality. Journal of Experimental Education, 68, 1521-1558.

Pekrun, R. (2000). A social-cognitive, control-value theory of achievement emotions. In J. Heckhausen (Ed.), Motivational psychology of human development (pp. 143-163). Oxford, England: Elsevier.

Pekrun, R. (2006). The control-value theory of achievement emotions: Assumptions, corollaries, and implications for educational research and practice. Educational Psychology Review, 18, 315-341.

Pekrun, R., Goetz, T., \& Frenzel, A. C. (2005). Achievement Emotions Questionnaire-Mathematics (AEQ-M)-User's manual. University of Munich, Department of Psychology.

Pekrun, R., Goetz, T., Titz, W., \& Perry, R. (2002). Academic emotions in students' self-regulated learning and achievement: A program of qualitative and quantitative research. Educational Psychologist, 37, 91-105.

Pohlmann, B., Möller, J., \& Streblow, L. (2004). Zur fremdeinschätzung von schülerselbstkonzepten durch lehrer und mitschüler [On students' self-concepts inferred by teachers and classmates]. German Journal of Educational Psychology, 18, 157-169.

Raudenbush, S. W., \& Bryk, A. S. (2002). Hierarchical linear models. Applications and data analysis methods (2nd ed.). Thousand Oaks, CA: Sage.

Raudenbush, S. W., Bryk, A. S., \& Congdon, R. (2007). HLM 6.04. Hierarchical linear and nonlinear modeling. Lincolnwood, IL: Scientific Software International.

Roseman, I. J. (2001). A model of appraisal in the emotion system: Integrating theory, research, and applications. In K. R. Scherer, A. Schorr, \& T. Johnstone (Eds.), Appraisal processes in emotion (pp. 68-91). Oxford, England: Oxford University Press.

Roseman, I. J., \& Smith, C. A. (2001). Appraisal theory: Overview, assumptions, varieties, controversies. In K. R. Scherer, A. Schorr, \& T. Johnstone (Eds.), Appraisal processes in emotion (pp. 3-19). Oxford, England: Oxford University Press.

Scherer, K. R. (2001). Appraisal considered as a process of multilevel sequential checking. In K. R. Scherer, A. Schorr, \& T. Johnstone (Eds.), Appraisal processes in emotion (pp. 92-120). Oxford, England: Oxford University Press. 
Schutz, P. A., \& Lanehart, S. L. (Eds.). (2002). Emotions in education [Special issue]. Educational Psychologist, 37.

Schutz, P. A., \& Pekrun, R. (Eds.). (2007). Emotions in education. San Diego, CA: Elsevier.

Stevenson, H. W., \& Newman, R. S. (1986). Long-term prediction of achievement and attitudes in mathematics and reading. Child Development, 57, 646-659.

Vandenberghe, R., \& Huberman, A. M. (Eds.). (1999). Understanding and preventing teacher burnout. Cambridge, England: Cambridge University Press.

Weiner, B. (1985). An attributional theory of achievement motivation and emotion. Psychological Review, 92, 548-573.

Wigfield, A., Battle, A., Keller, L. B., \& Eccles, J. S. (2002). Sex differences in motivation, self-concept, career aspiration, and career choice: Implications for cognitive development. In A. McGillicuddyDe Lisi \& R. de Lisi (Eds.), Biology, society, and behaviour: The development of sex differences in cognition (pp. 93-124), Westport, CT: Ablex.

Wild, T. C., Enzle, M. E., \& Hawkins, W. L. (1992). Effects of perceived extrinsic versus intrinsic teacher motivation on student reactions to skill acquisition. Personality and Social Psychology Bulletin, 18, 245-251.

Wild, T. C., Enzle, M. E., Nix, G., \& Deci, E. L. (1997). Perceiving others as intrinsically or extrinsically motivated: Effects on expectancy formation and task engagement. Personality and Social Psychology Bulletin, 23, 837-848. 